ties.) But even though NIH research may be the largest single component of the world's biomedical research, the implicit assumption that it is both a self-sufficient and a self-contained enterprise is a serious mistake.

At the least, it will give offence elsewhere, in places where the loss of talented people to NIH seems to be endemic, for example. More seriously, especially when NIH boasts in its plan of having one of the "most aggressive" of technology transfer operations in the US government, this chauvinistic view of NIH's role promises endless repetitions of the last year's tactless decision to patent partial genome sequences. Nobody will complain if NIH's endeavours help to create a still more prosperous biomedical industry in the United States; given the multinational character of the enterprises concerned, others will also benefit. But the full exploitation of the new knowledge now accumulating will outstrip even NIH's resources, however they may be augmented by the US Congress. NIH would have been more winning of opinion outside Washington if it had referred occasionally to its need of partnerships with other smaller, but not negligible, biomedical research enterprises.

\section{Why not plutonium?}

The time has come to think again, and constructively, about plutonium as a nuclear fuel.

WHo, other than some Japanese, says that Japan is not imaginative? While most other industrialized countries have given up building nuclear power stations and have even resolved to dismantle those already completed, Japan has been increasing nuclear generation. Now it proposes building a number of fast reactors so as make some use of the fissile material locked up in nuclear weapons in the republics of the former Soviet Union (see story on page 362). Even environmentalists should be delighted that these weapons surplus to requirements (and the provisions of bilateral arms control agreements with the United States) will not finish up as so many holes in the grounds or caverns deeper in the Earth's crust. But why are the Japanese proposing that their reactors should not fully use the neutrons generated in the fission process, but instead be operated in a way that simply converts the initial charge of fissile material into relatively short-lived radioisotopes?

In principle, a tonne of natural uranium is the energetic equivalent of one million tonnes of crude oil. Half a century ago, when people first dreamed that there would be a nuclear industry, it quickly became plain that winning the full energetic potential of uranium would require that isotopes such as uranium- 238 should first be converted into fissile material, most naturally the isotopes of plutonium (of which plutonium-239 is most suitable for making weapons). So, by the $1950 \mathrm{~s}$, every nuclear programme spelled out a prospect of how fissile material would be extracted from spent thermal reactor fuel and used for driving fast reactors designed not simply for the production of energy but also for the conversion of natural (or even depleted) uranium into further fissile material, plutonium as it happens.

Japan's decision not to follow that route in its proposal for disposing of unwanted Russian bombs stems partly from its wish not to be thought by other states to be stockpiling plutonium, which has acquired a bad name comparable only with that of the chemical called 'dioxin'. (There are economic reasons as well; secure storage costs money and, more important, stockpiling plutonium leaves economic resources unused.) But is it not an offence against reason that restraints of this kind should determine the ways in which economic resources are now used? Given the threat of global warming and the likelihood that countries with the technical competence of Japan will operate fast reactors safely, would it not be preferable to dust off the careful studies carried out in the 1970s of how plutonium could be safely stored in internationally secure repositories against the time when its use as a source of energy would be realistic?

\section{Recession without end}

Governments, especially the British, should be more realistic about the ending of the recession.

THE British government is going through a bad patch because it keeps promising that the long recession is about to end, only then to discover that it does not. It would be well advised to promise something else, perhaps a celebration to mark the turn of the next century, which is only seven and a half years away. The explanation of this state of affairs is well catalogued. The clamant need for the industrialized West to invest in Central Europe and the Commonwealth of Independent States, not to mention the really poor countries of the world, comes at a time when people are still burdened by debts assumed in the heady 1980s and also fearful for their jobs. In the circumstances, it is remarkable that the economies of two-thirds of the members of the Organisation for Economic Cooperation and Development (OECD) are still growing, if more modestly than in the recent past. Britain is one of those that is not.

But that is not just bad luck, nor does it imply that the consequences will be unimportant. The high rate of commercial bankruptcy will radically alter the pattern of industrial activity and will thus shape the pattern of the economy in which growth resumes when the recession eventually ends. For those affected, it is small comfort that the process is simply a further adjustment in the process by which Adam Smith's division of labour between interdependent mercantile states would eventually make a prosperous place of Europe as a whole. How to reconcile to that prospect the host now clamouring for British exit from the European Monetary System? By making sure that those still able to sell goods on world markets, even when $£ 1$ is worth DM2.95, are adequately patted on the back. 